\title{
Contraceptive Continuation, Pregnancy and Abortion Rate Two Years after Post Abortion Counselling
}

\author{
Ana Laura Carneiro Gomes Ferreira1, Mariana Moreira Boa-Viagem², \\ Ariani Impieri Souza1,2* \\ ${ }^{1}$ Women's Health Research Department of the Instituto de Medicina Integral Prof. Fernando Figueira (IMIP), \\ Recife, Brazil \\ ${ }^{2}$ Medical School of Faculdade Pernambucana de Saúde (FPS), Recife, Brazil \\ Email: ${ }^{*}$ ariani@imip.org.br
}

Received 1 January 2015; accepted 23 February 2015; published 27 February 2015

Copyright (C) 2015 by authors and Scientific Research Publishing Inc.

This work is licensed under the Creative Commons Attribution International License (CC BY). http://creativecommons.org/licenses/by/4.0/

(c) (i) Dpen Access

\section{Abstract}

Objectives: To estimate the contraceptive use rate, pregnancy and abortion rate two years after post abortion counselling. Methods: In this current paper we conducted a cross-sectional study from September to December 2011 among women who participated of original randomized trial. In this study 118 women who had been allocated in the group that received the personalized contraceptive counselling and 103 women who had been allocated in the group that received standard counselling service were contacted by phone. The analyzed variables were the use of contraceptive methods, reasons for not using them, satisfaction in used method, and occurrence of pregnancy and abortion. Results: The pregnancy rate was lower in the personalized counselling group $(p=0.022)$, whereas abortion $(p=0.543)$ and contraceptive use rate $(p=0.270)$ had no difference between groups. The overall contraceptive use rate was high in both groups and the injectable method use rate was higher in personalized counselling group $(p=0.004)$. Conclusions: Two years after the intervention the pregnancy rate was lower in personalized counselling group. The contraceptive use rate had no difference between the groups, except for the injectable which the use rate was higher in the personalized counselling group. These results could be encouraging because the intervention improved the uptake of one of the long-acting methods of contraception.

\section{Keywords}

Counselling, Education and Training, Family Planning Service Provision, Abortion

\footnotetext{
${ }^{*}$ Corresponding author.
}

How to cite this paper: Ferreira, A.L.C.G., et al. (2015) Contraceptive Continuation, Pregnancy and Abortion Rate Two Years after Post Abortion Counselling. Open Journal of Obstetrics and Gynecology, 5, 135-141. 


\section{Introduction}

Unsafe abortion continues to be a serious public health problem worldwide, particularly in developing countries, where abortion laws are restrictive and severe [1]-[3]. The lack of adequate knowledge on contraceptive methods, its incorrect or discontinuous use overtime can result in unplanned pregnancy thereby putting women at high risk of unsafe abortion. There is no doubt that addressing the unmet need for post-abortion family planning counselling and services will contribute to the reduction of maternal morbidity and mortality [4] [5].

According to the dossier about the reality of unsafe abortion in Pernambuco, Brazil, in the period between 2003 and 2007, abortion was responsible for 9.7\% of maternal deaths. In 2007, two cities in the Region, Recife and Petrolina, had the highest incidence rates of unsafe abortion registering $13 \%$ and $15 \%$ on obstetric hospitalizations due to abortion, respectively [6].

The post-abortion moment is a unique opportunity for contraceptive advice therefore, returning to health service, the women seek guidance on their health and are more motivated for compliance [7]. At this moment, counselling should be emphasized on education and information, enriching contraceptive need for each woman. The provision of contraceptive method is another factor that contributes to the adherence [7] [8].

A systematic review showed that there is no evidence on the use of post-abortion family planning counseling in low-income countries as a strategy to address the problem of unsafe abortion and its harmful consequence, but after receiving post-abortion family planning counseling, women accepted or used a broad range of types of modern contraceptive, including long-acting methods [1].

The adherence and the correct use of contraceptive methods can be influenced by a complex network from the access to health service to the provider-patient relationship, considering beliefs and myths about contraception [9]. These factors should then guide a personalized counselling and improve its effectiveness.

We aimed to estimate on the overall contraceptive use rate, the pregnancy and abortion rate, the use rate of each method, the reasons for non-using and the satisfaction of the used contraceptive method two years after a personalized post-abortion contraceptive counselling and compared with a standard counselling.

\section{Methods}

A cross-sectional study was conducted among 221 women who participated in the original randomized trial at Instituto de Medicina Integral Prof. Fernando Figueira (IMIP), in Recife, Northeast region of Brazil. We invited all women who had undergone any kind of abortion at any of the five public maternities in Recife to participate in this research. In the original intervention study women were allocated in two groups: The first group received a personalized and comprehensive post-abortion contraceptive counselling and the second one received a standard contraceptive counselling. The randomization procedure was performed using a random number table. The provider was informed about the allocation only after the admission interview.

The personalized post-abortion contraceptive counselling comprised a face-to-face counselling regarding the individual's contraceptive history and needs. This was based on: 1) The information about advantages and disadvantages of all types of contraceptives methods available; 2) Experience with the last method used and expectations, beliefs related to contraception; 3) Free provision of the chosen method.

The standard counselling comprised an educational group counselling about contraceptive methods and their side effects and the chosen method was given at no cost. Details of the original intervention study have been described previously [7].

From September to December 2011, two years later, 118 women from the personalized and comprehensive post abortion contraceptive counselling and 103 from the standard contraceptive counselling group. All the participants were contacted by phone and 25 could not be located.

The analyzed variables were the use of contraceptive method, reasons for not using the contraceptive methods, satisfaction of used method, and occurrence of pregnancy and abortion. The variables were assessed by the group from the original trial. The analysis was performed using Epi Info 3.5.3. The statistical analysis was performed using absolute and relative frequency of the socio-demographic variables and reason not use contraceptive reasons for not using the contraceptive method. To compare the frequency of the outcomes rate and contraceptive methods use rate among the groups, the prevalence ratio (PR) was calculated at the level of 5\% significance. This study was approved by the Institutional Review Board at IMIP. All participants agreed to take part in the study. 


\section{Results}

Table 1 shows the socio-demographic characteristics and reproductive history of the study population. No statistically significant difference was observed in the characteristics investigated between groups.

The pregnancy rate in standard counselling group was higher than personalized counselling group $(p=0.022)$, whereas abortion $(p=0.543)$ and contraceptive use rate $(p=0.270)$ had no difference between groups (Table 2).

To assess the contraceptive use rate by method, we observed that women in personalized counselling group had almost three times more chances to use quarterly injectable when compared with standard counselling group $(p=0.004)$. In relation to all other contraceptive methods, there was no difference between the groups (Table 3).

The no method-related reasons, as access to health service, were the most mentioned reason for not using the method (40.3\%), whereas the method related reasons were the least mentioned (14.1\%) (Table 4).

The degree of satisfaction with the method was high in both groups, and $86.4 \%$ of the women reported being "very satisfied" or "satisfied" with the method in use (Results not shown in the table).

Table 1. Sociodemographic characteristics and reproductive history of women in the intervention and control groups.

\begin{tabular}{cccc}
\hline Characteristics & Personalized counselling & Standard counselling & p value \\
\cline { 2 - 3 } Live in Recife (\%) & $\mathrm{N}=118$ & $\mathrm{~N}=103$ & 0.60 \\
Age, years (mean \pm SD) & 57.7 & 61 & 0.37 \\
Schooling, years (mean \pm SD) & $26.2 \pm 6.8$ & $27.6 \pm 6,8$ & 0.58 \\
Employed (\%) & $10.2 \pm 2.7$ & $4.8 \pm 2.9$ & 0.44 \\
Cohabitating (\%) & 48.8 & 79.7 & 0.08 \\
History of previous abortion (\%) & 69.9 & 30.1 & 0.39 \\
Number of children (mean \pm SD) & 25.2 & $0.9 \pm 1.1$ & 0.37 \\
\hline
\end{tabular}

Table 2. Pregnancy, abortion and contraceptive use rate.

\begin{tabular}{|c|c|c|c|c|c|c|c|}
\hline \multirow{3}{*}{ Variables } & \multirow{2}{*}{\multicolumn{2}{|c|}{$\begin{array}{c}\text { Personalized counselling } \\
\qquad \mathrm{n}=118\end{array}$}} & \multicolumn{5}{|c|}{ Standard counselling } \\
\hline & & & & & & & \\
\hline & $\mathrm{N}$ & $\%$ & $\mathrm{~N}$ & $\%$ & PR & CI 95\% & $\mathrm{p}$ value \\
\hline Pregnancy & 31 & 26.3 & 42 & 40.8 & 0.52 & $0.28-0.95$ & 0.022 \\
\hline Abortion & 8 & 6.8 & 5 & 4.8 & 1.43 & $0.41-5.21$ & 0.543 \\
\hline Contraceptive use & 89 & 75.4 & 84 & 81.5 & 0.69 & $0.34-1.40$ & 0.270 \\
\hline
\end{tabular}

Table 3. Current contraceptive use according to the methods.

\begin{tabular}{|c|c|c|c|c|c|c|c|}
\hline \multirow{2}{*}{ Method } & \multicolumn{2}{|c|}{ Personalized counselling } & \multicolumn{2}{|c|}{ Standard counselling } & \multirow[b]{2}{*}{ PR } & \multirow[b]{2}{*}{ CI 95\% } & \multirow[b]{2}{*}{$\mathrm{p}$ value } \\
\hline & $N=118$ & $\%$ & $\mathrm{~N}=103$ & $\%$ & & & \\
\hline Condom & 20 & 17.0 & 18 & 17.5 & 0.96 & $0.45-2.05$ & 0.917 \\
\hline Quarterly injectable & 32 & 27.1 & 12 & 11.7 & 2.82 & $1.30-6.23$ & 0.004 \\
\hline Oral hormonal contraceptive & 21 & 17.8 & 24 & 23.3 & 0.71 & $0.35-1.44$ & 0.311 \\
\hline Others $^{*}$ & 11 & 9.3 & 10 & 9.7 & 0.96 & $0.36-2.56$ & 0.922 \\
\hline No methods or pregnant currently & 34 & 28.8 & 39 & 37.9 & 0.76 & $0.52-1.11$ & 0.153 \\
\hline
\end{tabular}

*Lactation-Amenorhea Method (n-6); Withdraw (n = 4); IUD (n = 2); Tubal Ligation (9). 
Table 4. Reasons for not using contraceptive method.

\begin{tabular}{cccccccc}
\hline \multirow{2}{*}{ Reason for not using } & \multicolumn{2}{c}{ Personalized counselling } & \multicolumn{2}{c}{ Standard counselling } & \multicolumn{2}{c}{ Total } \\
\cline { 2 - 7 } & $\mathrm{N}$ & $\%$ & $\mathrm{~N}$ & $\%$ & $\mathrm{~N}$ & $\%$ \\
\hline Desire to become pregnant & 13 & 38.2 & 13 & 33.3 & 26 & 45.6 \\
Method-related reasons & 2 & 5.9 & 6 & 15.4 & 8 & 14.1 \\
Do not worry about or access to health service problem & 19 & 55.9 & 20 & 51.3 & 23 & 40.3 \\
\hline
\end{tabular}

\section{Discussion}

This study showed a new assessment of contraceptive use rate two years after post-abortion contraceptive counselling intervention study [7]. We have previously reported results of the effects on contraceptive use after six months of a personalized and comprehensive post-abortion contraceptive counselling. In that previous study, the personalized counselling demonstrated higher contraceptive use rate. In this current analysis abortion and contraceptive use rate had no difference between the groups, but the pregnancy rate was lower in the personalized counselling group. This suggests that the personalized counselling received two years before could have been protected of an unplanned pregnancy and its harmful consequences, even though among the reasons for not using the method, the desire to become pregnant was the main reason mentioned.

On the other hand, the gap between the post-abortion contraceptive counselling and this second assessment, two years after post-abortion contraceptive counseling, may not have had the same effect in the abortion and method use rate. This reinforces the need for contraceptive counselling services in which women should be followed and monitored in shorter intervals [10].

A systematic review published in 2011, that selected studies from low-income countries, found no sufficient evidence on the impact of post-abortion contraceptive counselling on repeat abortions and unplanned pregnancies, but there is some yet promising evidence on the impact of contraceptive counseling on acceptance or use of contraception [1]. This review suggests that this is due to lack of good quality evaluations measuring outcomes which are important for future programming and police-making.

The personalized post-abortion contraceptive counselling which emphasizes the advantages and disadvantages of each method every six months could avoid the discontinuation of the method and occurrence of unplanned pregnancies and reduce women's recourse to unsafe abortion [7] [8]. Women could then obtain greater information as to reproductive planning and, subsequently, decision making in an informed and voluntary way [11] [12]. Despite this, the final decision regarding the use of any method is known to be complex and difficult to be explained in the light of quantitative studies [9] [12] [13]. Therefore the individual's desire or need to avoid pregnancy may change in the course of women's reproductive life. Patients may fail to use the method because they become less interested or motivated in preventing pregnancy, because they no longer have a sexual partner or the method requires possession of some basic knowledge and skills if they are to be used [1] [14].

A French survey designed to measure contraceptive practices and rates of abortion among post-abortion women or post unwanted pregnancy found high rates of discontinuation of contraceptive methods for methodrelated reasons. The discontinuation rate found was higher in method switching rather than contraceptive abandonment altogether [15]. Their estimates were higher than those generally reported in clinical trials [16] [17] such as our results the method-related reasons for not using contraceptive method were less mentioned than any other reasons, regardless of the method.

The use of quarterly injectable was greater in the personalized counselling group. Injectable is not widely used among Brazilian women, [18] suggesting that the frequency of women in use of injectable after two years could still be due to the intervention. Furthermore, the post-abortion period may motivate the choice of highly effective and long-acting reversible contraceptives (LARC) as the injectables [19]-[21]. To use a LARC method is also in accordance with the consensus statement drawn up by International Federation of Gynecology and Obstetrics (FIGO) Initiative for the Prevention of Unsafe Abortion and its consequences in the post abortion care. FIGO recommends to provide LARC before women leave the health care facility [22]. Furthermore, studies that report LARC use are more useful outcome for policy-makers than acceptance of self-administering methods, such as condoms [1].

Despite the still low frequency of condom use compared with pill and injectable method, its acceptance has 
increased over the past years, especially after the discovery of human immunodeficiency virus (HIV) [23].

Most surveyed women were married and the condom use rate observed was the third method used and this could be a concern. A barrier method has been used as an option for temporary method among couples in the initial stages of the relationship even in population where HIV is highly prevalent. Condom is more used by women in unstable relationships and depends on the confidence to negotiate condom use [24]. A study carried out in Malaysia about contraceptive choice and acceptability showed a lower proportion of condom use (less than $10 \%$ ) and willingness to use contraception does not interfere in sexual intercourses [25].

Regarding women who chose oral contraceptive, differences between groups were not observed. This could be explained by the fact that the pill is a popular method among Brazilian women who use it regardless of counselling, follow up, or prescription [3] [11]. Most women were already aware of pills by family or friends, in favor of the use, regardless of the prescription [8]. In Brazil, since the 1960s, the pill has been widely commercialized, and the investment of pharmaceutical industry research on hormonal contraception produces pills with lower doses of hormones without interfering with the effectiveness of the method, contributed by the acceptance of the Brazilian women [26].

Although the adherence to contraceptive method is related to previous contraceptive experiences, the perception and satisfaction of women with the method have become an important factor to its continuous use [7] [15]. The degree of satisfaction with the use of the method was high in both groups. This may have occurred because of contraceptive choices being made by themselves as users and mainly among reversible methods with a few side effects and large clinical efficacy [11] [12].

There are some limitations in the design of this study. It was not a follow up of the original study, but we conducted a cross sectional study with the same participants. A recent review reported that the follow up could be incorporated to assess retention of knowledge during time [10]. Although another review reported no study followed women up for longer than one year [1].

\section{Conclusion}

Two years after contraceptive counselling, the pregnancy rate was lower in personalized counselling group. The abortion and contraceptive use rate had no difference between groups. The overall contraceptive use rate and the satisfaction with the method were high, and there was no difference between groups, except for the injectable which the use rate was higher in the personalized counselling group. These findings suggest that post abortion contraceptive counselling programs could be effective to maintain the use in long-acting methods.

\section{Competing Interests}

The authors have no competing interest.

\section{Acknowledgements}

We would like to thank Conselho Nacional de Desenvolvimento Científico e Tecnológico (CNPq) for the scholarship to MMBV.

\section{References}

[1] Tripney, J., Schucan Bird, K., Kwan, I. and Kavanagh, J. (2011) The Impact of Post-Abortion Care Family Planning Counselling and Services in Low-Income Countries: A Systematic Review of the Evidence (Technical Report). EPPICentre, Social Science Research Unit, Institute of Education, University of London, London. http://eppi.ioe.ac.uk/cms/LinkClick.aspx?fileticket=X_JbXQTVDEQ\%3D\&tabid=3062\&mid=5694

[2] Ministry of Health of Brasil (2014) Abortion Report and Public Health-20 Years of Research in Brazil. http://www.estadao.com.br/ext/especiais/2008/04/pesquisa_aborto.pdf

[3] Leite, I.C. and Gupta, N. (2007) Assessing Regional Differences in Contraceptive Discontinuation, Failure and Switching in Brazil. Reproductive Health, 4, 6. http://dx.doi.org/10.1186/1742-4755-4-6

[4] Espejo, X., Tsunechiro, M.A., Osis, M.J., Duarte, G.A., Bahamondese, L. and Souza, M.H. (2003) Knowledge Adequacy on Contraceptives among Women in Brazil. Revista de Saúde Pública, 37, 583-590. http://dx.doi.org/10.1590/S0034-89102003000500006

[5] World Health Organization (2012) Trends in Maternal Mortality: 1990 to 2010. WHO, UNICEF, UNFPA and The World Bank, Geneva. 
http://whqlibdoc.who.int/publications/2012/9789241503631_eng.pdf?ua=1

[6] Gall, B., Viana, P. and Melo, N. (2011) Dossier on the Reality of Unsafe Abortion in Pernambuco: The Impact of the Illegality of Abortion on Women's Health in the Health Services of Recife and Petrolina. Recife, Pernambuco. http://www.ipas.org/ /media/Files/Ipas\%20Publications/5statesENG.ashx

[7] Ferreira, A.L.C.G., Souza, A.I., Pessoa, R.E. and Braga, M.C. (2011) The Effectiveness of Contraceptive Counselling for Women in the Postabortion Period: An Intervention Study. Contraception, 84, 377-383. http://dx.doi.org/10.1016/j.contraception.2011.02.003

[8] Rash, V., Yambesi, F. and Kipingili, R. (2005) Scaling up Postabortion Contraceptive Service-Results from a Study Conducted among Women Having Unwanted Pregnancies in Urban and Rural Tanzania. Contraception, 72, 377-382. http://dx.doi.org/10.1016/j.contraception.2005.04.015

[9] Dehlendorf, C., Levy, K., Kelley, A., Grumbach, K. and Steinauer, J. (2013) Women’s Preferences for Contraceptive Coun- selling and Decision Making. Contraception, 88, 250-256. http://dx.doi.org/10.1016/j.contraception.2012.10.012

[10] Lopez, L.M., Steiner, M., Grimes, D.A., Hilgenberg, D. and Schulz, K.F. (2013) Strategies for Communicating Contraceptive Effectiveness. Cochrane Database System Review, 4, Article ID: CD006964. http://dx.doi.org/10.1002/14651858.CD006964.pub2

[11] Carreno, I., Dias-da-Costa, J.S., Olinto, M.T.A. and Meneghel, S. (2006) Use of Contraceptive Methods by Sexually Active Women in São Leopoldo, Rio Grande do Sul, Brazil. Cadernos de Saúde Pública, 22, 1101-1109. http://dx.doi.org/10.1590/S0102-311X2006000500023

[12] Upadhyay, U.D., Brown, B.A., Sokoloff, A. and Raine, T.R. (2012) Contraceptive Discontinuation and Repeat Unintended Pregnancy within 1 Year after an Abortion. Contraception, 85, 56-62. http://dx.doi.org/10.1016/j.contraception.2011.05.009

[13] Cecatti, J., Guerra, G., Sousa, M.H. and Menezes, G.M.S. (2010) Abortion in Brazil: A Demographic Approach. Revista Brasileira de Ginecologia e Obstetrícia, 32, 105-111. http://dx.doi.org/10.1590/S0100-72032010000300002

[14] Ferreira, A.L., Lemos, A., Figueiroa, J.N. and Souza, A.I. (2009) Effectiveness of Contraceptive Counselling of Women Following an Abortion: A Systematic Review and Meta-Analysis. European Journal of Contraception and Reproductive Health Care, 14, 1-9. http://dx.doi.org/10.1080/13625180802549970

[15] Moreau, C., Bouyer, J., Bajos, N., Rodríguez, G. and Trussell, J. (2009) Frequency of Discontinuation of Contraceptive Use: Results from a French Population-Based Cohort. Human Reproduction, 24, 1387-1392.

http://dx.doi.org/10.1093/humrep/dep027

[16] Trussell, J. and Vaughan, B. (1999) Contraceptive Failure, Method-Related Discontinuation and Resumption of Use: Results from the 1995 National Survey of Family Growth. Family Planning Perspectives, 31, 64-72.

http://www.guttmacher.org/pubs/journals/3106499.html http://dx.doi.org/10.2307/2991641

[17] Vaughan, B., Trussell, J., Kost, K., Singh, S. and Jones, R. (2008) Discontinuation and Resumption of Contraceptive Use: Results from the 2002 National Survey of Family Growth. Contraception, 78, 271-283. http://dx.doi.org/10.1016/j.contraception.2008.05.007

[18] Pirotta, K.C.M. and Schor, N. (2004) Reproductive Intentions and Fertility Regulation Practices among University Students. Revista de Saúde Pública, 38, 495-502. http://dx.doi.org/10.1590/S0034-89102004000400003

[19] Prata, N., Bell, S., Holston, M., Gerdts, C. and Melkamu, Y. (2011) Factors Associated with Choice of Post-Abortion Contraception in Addis Ababa, Ethiopia. African Journal of Reproductive Health, 15, 51-57.

[20] Rose, S.B., Wei, Z., Cooper, A.J. and Lawton, B.A. (2012) Peri-Abortion Contraceptive Choices of Migrant Chinese Women: A Retrospective Review of Medical Records. PLOS ONE, 7, e40103.

[21] Kalyanwala, S., Acharya, R. and Francis-Zavier, A.J. (2012) Adoption and Continuation of Contraception Following Medical or Surgical Abortion in Bihar and Jharkhand, India. International Journal Gynecology \& Obstetrics, 118, S47S51. http://dx.doi.org/10.1016/j.ijgo.2012.05.010

[22] Gemzell-Danielsson, K., Kallner, H.K. and Faúndes, A. (2014) Contraception Following Abortion and the Treatment of Incomplete Abortion. International Journal of Gynecology \& Obstetrics, 126, S52-S55. http://dx.doi.org/10.1016/j.ijgo.2014.03.003

[23] Duarte, G.A., de Alvarenga, A.T., Osis, M.J., Faúndes, A. and de Sousa, M.H. (2003) Male Participation in Contraceptive Use. Cadernos de Saúde Pública, 19, 207-216. http://dx.doi.org/10.1590/S0102-311X2003000100023

[24] Exavery, A., Kanté, A.M., Jackson, E., Noronha, J., Sikustahili, G., Tani, K., et al. (2012) Role of Condom Negotiation on Condom Use among Women of Reproductive Age in Three Districts in Tanzania. BMC Public Health, $12,1097$. http://dx.doi.org/10.1186/1471-2458-12-1097 
[25] Shiely, F. and Saifuddin, M.S. (2014) Contraceptive Choice and Acceptability: The Future for STI Risk in Kelantan, Malaysia. International Journal of STD \& AIDS, 25, 219-227. http://dx.doi.org/10.1177/0956462413497699

[26] Manica, D.T. (2011) The Denaturalization of Menstruation: Contraceptive Hormones and Technoscience. Horizontes Antropológicos, 17, 197-226. http://dx.doi.org/10.1590/S0104-71832011000100007 
Scientific Research Publishing (SCIRP) is one of the largest Open Access journal publishers. It is currently publishing more than 200 open access, online, peer-reviewed journals covering a wide range of academic disciplines. SCIRP serves the worldwide academic communities and contributes to the progress and application of science with its publication.

Other selected journals from SCIRP are listed as below. Submit your manuscript to us via either submit@scirp.org or Online Submission Portal.
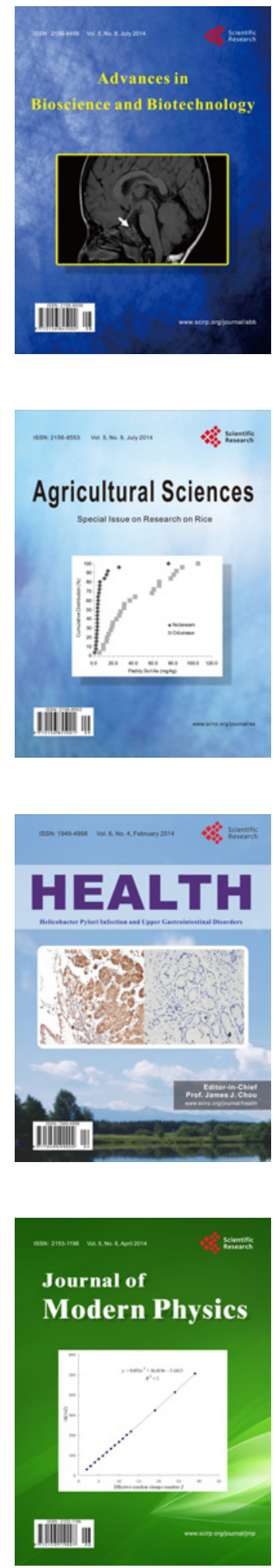
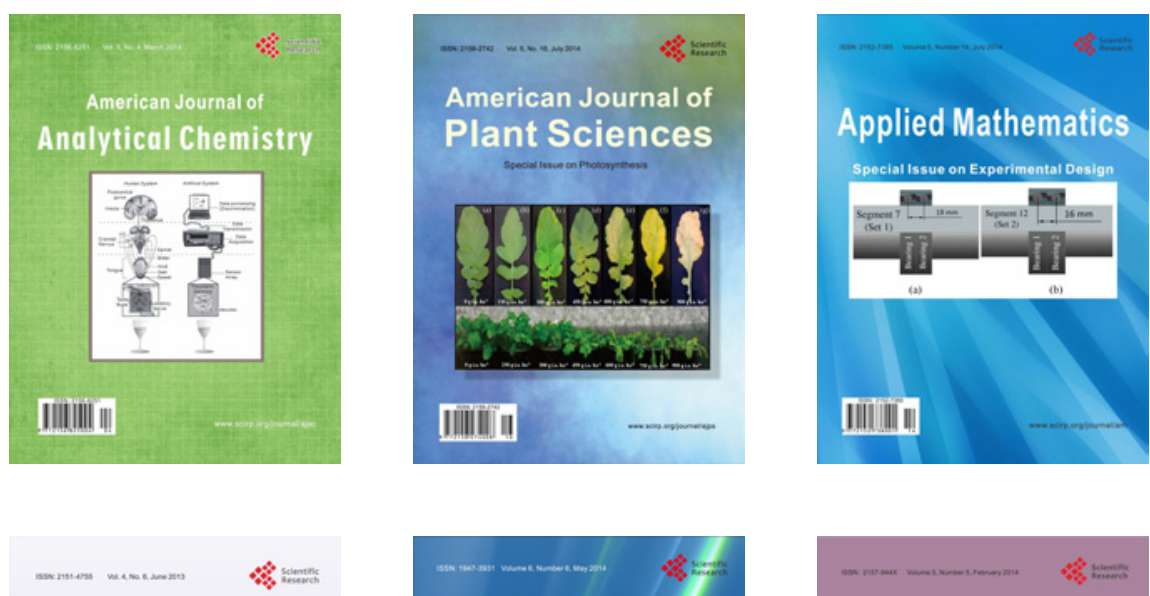

Creative Education
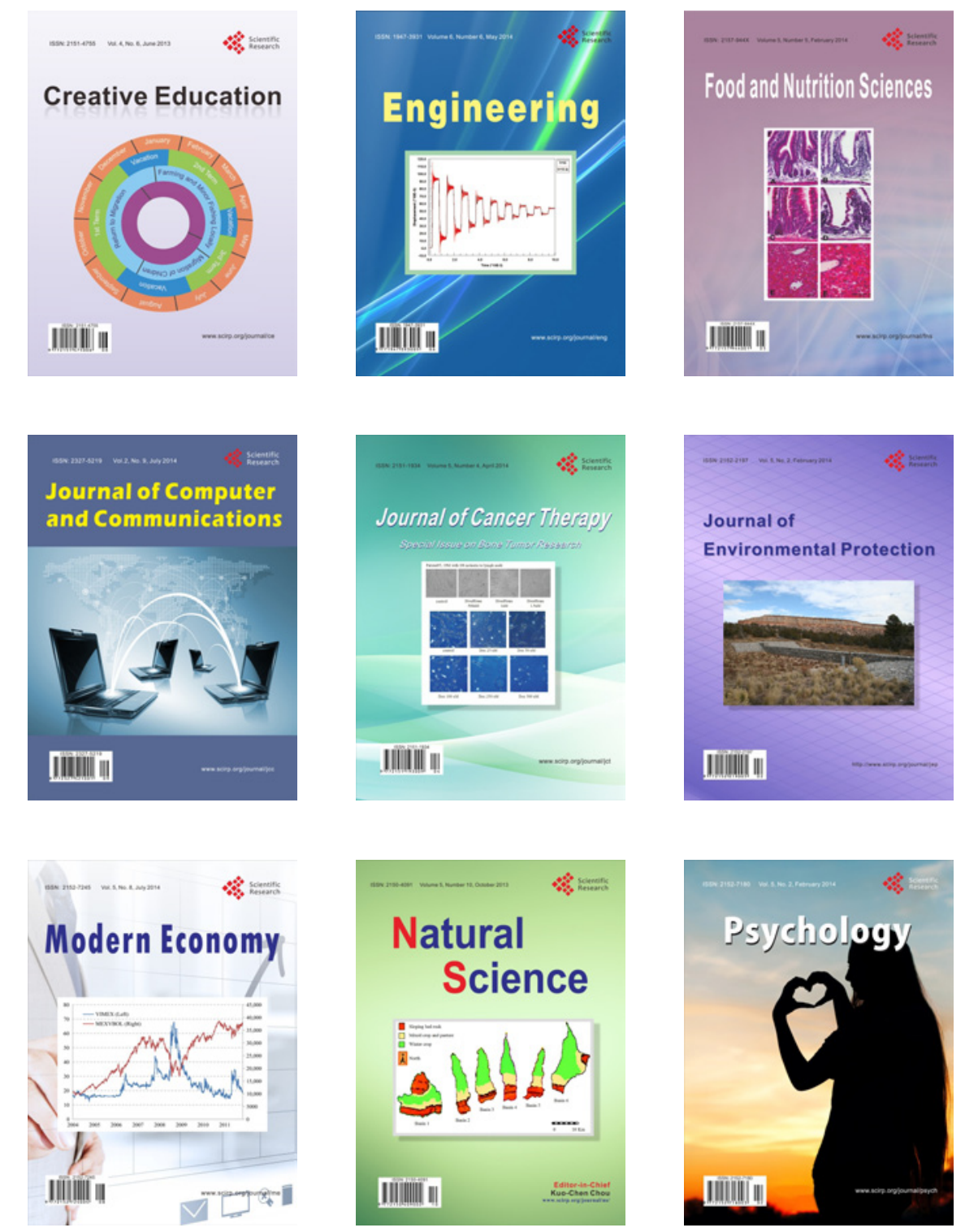